\title{
Research on Dilemma in Construction of Social Pension Service System in Hainan Province and Relevant Countermeasures
}

\author{
Zhilan Wang \\ Qiongzhou University, Sanya, 572022, China
}

\begin{abstract}
Aging of population is an inevitable state of social development of human being as well as an inevitable product of economic and social development. Currently, aging of population has already become a major issue blocking economic and social development of Hainan Province. This issue brought forth unprecedented challenges to works in all aspects. At the same time, it also exposed lots of deficiencies in the construction of economic society. On this basis, the author in this paper mainly made a research on dilemma in the construction of social pension service system in Hainan Province and relevant countermeasures.
\end{abstract}

Key words: Hainan, social pension service system, construction, countermeasure Family planning is one of basic state policies in China. In the specific period, this policy effectively controlled over-increase in Chinese population. However, its negative effects gradually appear at present, including aggravated aging of population. Besides, the progress in medical technology is also an important factor for aggravated aging of population. As everyone knows, the aged need material life. At the same time, they can not be separated from mental comfort. For Chinese pension system, this is a new challenge. For better guarantee of the life of old people in twilight years, it is in urgent need of listing the issue of pension into social responsibility. As an important economic province in China, Hainan Province is one of cities into the aged society in recent years. In terms of the construction of social pension service system, Hainan is confronted with great pressure. Therefore, it is of important practical significance for the discussion on dilemma in the construction of social pension service system in Hainan Province and relevant countermeasures.

\section{Current Situation of Aging and the Construction of Social Pension Service} \section{System in Hainan Province}

Since its formulation, China's family planning has been widely promoted across the country. Hainan Province is one of provinces in positive response to this policy. Although family planning is a compulsory policy, its effect is undeniable. It reduced the birth rate of Chinese population. To some extent, the policy of sound child rearing also improved the quality of 
Chinese population. However, the long-term promotion of family planning weakened people's concept of child-bearing, resulting in the growth rate of new population less then the aging rate in China. If this trend continues, China will be faced with new population issues. According to the data, by 2015, the number of old people aged over 80 will reach as high as 170 thousands in Hainan Province; and the old aging proportion will reach 14.66\%. Aging and old aging of population leads to the increase in numerous disabled and semi-disabled seniors, aggravating the nursing pressure of Hainan. With employment of children in considerable families, the number of empty-nest elderly increased. How to take care disabled, semi-disabled, empty-nest and elderly people living alone becomes an issue concerned by both the government and the society.

To this end, Hainan Province took a series of measures to response to increasingly serious situation of aging. In terms of system, Hainan Province continuously perfected the pension system, made special treatment strategies for the old, issued relevant policies and measures and provided guarantee to the life of old people. The construction of social pension service infrastructures got rapid development in Hainan Province. In terms of infrastructure, Hainan invested considerable funds into the construction and reconstruction of nursing homes. Moreover, Hainan also encouraged the development of private pension institutions. Nowadays, private pension institutions have already become an integral part of the pension system of Hainan Province.

\section{Dilemma in the Construction of Social Pension Service System in Hainan Province}

\section{Incomplete construction of service organization system and institutional system}

To solve social issues caused by aging of population, Hainan Province established a basic pension service system. A reasonable and mature pension service system should be led by the government and participated by all kinds of social development under coordinated division of labor. However, various departments of Hainan pension service system failed to reach effective communication and cooperation. In terms of overall operation and management, they still have many defects. For example, there are many disabled seniors among aging population, who are confronted with many emergencies. However, Hainan's pension service failed to make effective and timely solutions or take special countermeasures while confronted with this category of issues. This is a potential threat for life health of the aged. 


\section{Fewer sources of social pension funds}

A major reason for incomplete pension system in Hainan Province is the issue of fund. In terms of its current situation, considerable funds are needed, if Hainan wants to realize diversified social pension services and give consideration to its comprehensiveness at the same time. Construction fund of Hainan's pension service is mainly sourced from fiscal appropriation, but the amount of fiscal appropriation is extremely limited. Moreover, the use of fund is restrained by regional and other factors. Viewed from the overall condition in China, donation from social and charity organizations is tantamount to drop in the bucket for the development of pension service. The construction of pension service has no the character of profit. Therefore, there are fewer enterprises and groups for investment. This part of fund is only enough to support the launch of pension works. However, the source of fund should be continuously expanded, so as to promote the development of pension undertakings to a larger extent. To this end, Hainan Province should make more efforts with respect to the source of fund and never passively wait for fiscal appropriation or social contribution. Instead, Hainan Province should establish and perfect the fund raising mechanism, set up a special fund for supporting the development of pension service, improve the utilization of fund and realize special fund for special purpose.

\section{Low professional service level of pension institutions}

At this stage, retirement organizations are incomplete in Hainan Province, with many defects in many aspects. On the one hand, most servers in the pension organizations are non-professionals in Hainan, such as part-timers and temporary workers. This category of personnel has a similarity: low professional ability. Moreover the mobility is comparatively great, extremely harmful to the construction of the pension service team. On the other hand, there is a shortage of professionals. They failed to take good care of old people. The shortage of professionals leads to the failure to take good care of the old in daily life as well as low quality and service level of pension service organizations. It becomes more serious for low pension service quality caused by the participation of inadequate professionals. Generally speaking, the construction of the institution pension service system is still in the relatively low development level in Hainan Province.

\section{Insufficient humanistic care in system management}

Considering fund, traffic and other issues, fewer pension organizations would be 
built in downtown. However, children and other family members of the old often lived in cities. That is to say, old people in pension organizations cannot frequently see their family members, which is harmful to their physical and psychological health. At ordinary days, old people in pension organizations contacted all servers and other old people. If this trend continues, they will feel boring and lack care from their relatives. Originally, birth, death, illness and old age are normal in life. However, all are old people in retirement organizations. Moreover, most are sicken old people. Therefore, they saw many deaths than ordinary persons. This aggravated their psychological burden to a large extent. If without timely settlement, these psychological problems will influence the heath of old people.

\section{Countermeasures for the Construction of Social Pension Service System in}

\section{Hainan Province}

\section{Strengthen the construction of pension service institutional system and improve the management standardization}

In 2013, Law of the People's Republic of China on the Protection of Rights and Interests of the Aged was modified. This is a good opportunity for the construction of the aged service system. We should grasp this opportunity to perfect relevant laws and regulations, construct a more comprehensive and more mature pension service system, enhance supervision, standardize the management mechanism and protect legal rights and interests of the aged. Relevant departments should lay emphasis on the standardization of pension service in terms of the construction of the pension service system and positively develop demonstration activities. On the basis of original principles, these departments should establish the rating evaluation system for retirement organizations and perform dynamic evaluation for the health, psychology and other conditions and all kinds of needs of the aged into these organizations, so as to develop various works accordingly.

\section{Enhance fund investment and establish a long-term mechanism}

Fund is served as the guarantee of perfection to pension service. Therefore, expenses of public pension organizations should be integrated into financial budget. For non-public retirement organizations, the governmental departments should encourage and support, give policy encouragement to enterprises, social groups and individuals to establish or operate retirement organizations, adopt the mode of construction upon public contribution and operation by enterprises and social groups or cooperative operation, flexibly allocate funds, facilities and personnel and 
promote diversified construction of the pension service system. To expand financing channels of the construction of pension service, relevant organizations can continuously explore for commercial value and attract more funds according to characteristics of retirement organizations. However, the precondition is to guarantee the controllability of all kinds of risks. It is not allowed to neglect potential risks for the purpose of attracting funds, so as to lay hidden risks to the construction of pension service. The purpose of the construction of pension organizations is to serve the public. Therefore, many issues can be solved, if folk funds can be attracted to the pension service industry. The construction of the pension service system needs long-term fund supports. The integration of expenses of public retirement organizations into financial budget and construction of a dynamic safeguard mechanism is served as an important means to solve the fund issue of public pension organizations. To encourage the development of private retirement organizations, the mode of direct subsidy or interest subsidy can be adopted. To attract funds from enterprises or social groups, reputation affirmation can be given. Moreover, it can be vigorously advocated in the society, making people to form fixed consciousness.

\section{Increase talent team construction and improve the specialized service level}

The shortage of professionals is a common problem of pension services in China. Generally, servers are low in quality and inadequate in professional knowledge and skills. For these issues, we should enhance the talent cultivation, construct a specialized service team, lay emphasis on enhancing the introduction of professional social workers and the training for professional theories and skills about social work, develop regular trainings, continuously strengthen skills of workers, and make relevant servers to master knowledge about social work, nursing and psychology. Besides, we can also offer professional courses and continuously make it stronger for the professional service team. Training materials are served as guidelines for the development of pension service training. Therefore, new textbooks should be prepared according to the requirements of the times. To guarantee the profession of our pension service, we should also implement the examination authentication system for professional qualification of nurses and occupational requirements for gerontological social work, perform employment with certificates and increase the professional level. Nurses are professional posts among pension service personnel, with higher requirements for both professional 
knowledge and experience. However, the current mechanism still integrates it into logistic skill posts in China. The salary is naturally the standard for logistic workers, which is harmful to their work enthusiasm. For this situation of shortage of pension servers, we can encourage volunteers to join in pension service through publicity. Students are served as a huge group. If students can be integrated into the volunteer team, they will bring forth new vitality to pension service. Moreover, government functionaries, party members and others should take the lead. The original intention of voluntary service is to serve the aged. As subjects of service, old people are only roles to receive such service. Those old people with capacity for action should also join in the volunteer team, especially for retired old people and veteran cadres. To some extent, this also enriched their life in twilight years and trained their self-help ability. With developed science and technology at present, the Internet should become an important tool for publicity and construction of relevant systems. It will bring forth more convenience for publicity and guidance of volunteer service works.

\section{Integrate cultural pension elements and improve the quality of social pension service}

At present, the aged need material life and mental \& cultural life at the same time. To advocate cultural pension, we should first advertise and perform ideological and political work for the aged with the help of grass-roots party branches, continuously promote the cultural pension mode and make pension service to have new vitality in the new era. In cultural pension, party members among the aged should play an important role and lead the development of cultural pension service. To guarantee the effective development of cultural pension, we should establish and perfect infrastructures and give hardware supports to various activities for the aged. For instance, the aged cultural groups, calligraphy associations or chess clubs should be established in the community. Moreover, we can also jointly hold all kinds of activities with other existing activity groups for the aged (such as sunset glow and calligraphy association for the aged), creating various kinds of opportunities for the aged and developing the activity atmosphere, so as to provide diversified platforms to old people with different needs from multiple levels and direction and make old people to set up healthy life attitudes, get and maintain good life styles and reduce loneliness and alienation of old people. In addition, we should also positively develop all kinds of cultural service activities beneficial for physical and 
psychological health of the aged and provide carriers and channels for entertainment of old people. Relevant organizations can also establish various platforms, promote cultural communication with old people and promote faster and more comprehensive development of cultural pension work.

\section{Conclusion}

Family planning is one of basic state policies in China. In the specific period, this policy effectively controlled over-increase in Chinese population. However, it becomes an important reason for the accelerated aging of Chinese population at present. Besides, the progress in medical technology is also a major factor for aggravated aging of population. Increasingly severe aging of population brought forth unprecedented challenges to Chinese social pension service system. The construction of pension service system is a piece of long-term work requiring policy supports from the government and positive participation of all social classes. Only continuous perfection of the pension system, improvement to the supervision and management mechanism and strengthening talent cultivation can guarantee smooth and comprehensive promotion of this great event concerning the public' life and descendants. Each person will be aged someday. The attention to pension work is about the attention to our future life.

\section{Acknowledgments}

This paper is the subject of planning for philosophy and social science in Hainan Province: Research on the Construction of Aged Society Pension Service System in Hainan Province (No.: HNSK (GJ) 13-130), the subject of planning for philosophy and social science in Hainan Province: Research on Difficulties in Comprehensive Construction of Well-to-do Society in Minority Areas in Hainan Province (No.: HNSK14-86), and the special subject of social work in Hainan Province of Qiongzhou University: Works of Aged Society and Construction of International Tourism Island (No.: QYSG201205) and Vocational Training Manual for Social Workers in Hainan Province (No.: QYSG201212).

\section{References:}

[1] Tang Xiaoying and Dong Bo, Analysis on Implementation Approach of Community Culture Pension Mode [J], Journal of Northwest A\&F University (Social Science Edition), 2011, (05);

[2] Singapore Aging Work Delegation, Office of Committee on Aging, Survey Report on Aging Work in Singapore [J], China Society Periodical, 2014, (10);

[3] Dong Hongya, Function Restructure of Retirement Organizations: Reflection on 
Harmonious Development of Social Pension Service Systems [J], Journal of Nanjing College for Population Programme Management, 2012, (01);

[4] Xu Dianbing and Sun Qi'ang, Further Consideration of Perfecting Social Pension Service Systems in China - Analysis on Investigation based on Current Situation of Pension Service in Jiangsu Province [J], Academia Bimestris, 2011, (06). 